\title{
ORGANIZACIÓN Y PROCESO LOGÍSTICO DE PRODUCTOS DENOMINADOS “ABARROTES” DE UN SUPERMERCADO
}

\section{ORGANIZATION AND LOGISTICS PROCESS OF PRODUCTS CALLED "ABARROTES" OF A SUPERMARKET}

Eloy Manuel Durand Durand; André Aguirre Cáceres, Bryan Germán Yoplac Fasanando; Jhonatan Morales Candela.

Estudiantes de la Universidad Ricardo Palma

Facultad de Ciencias Económicas y Empresariales

Escuela Profesional de Administración de Negocios Globales.

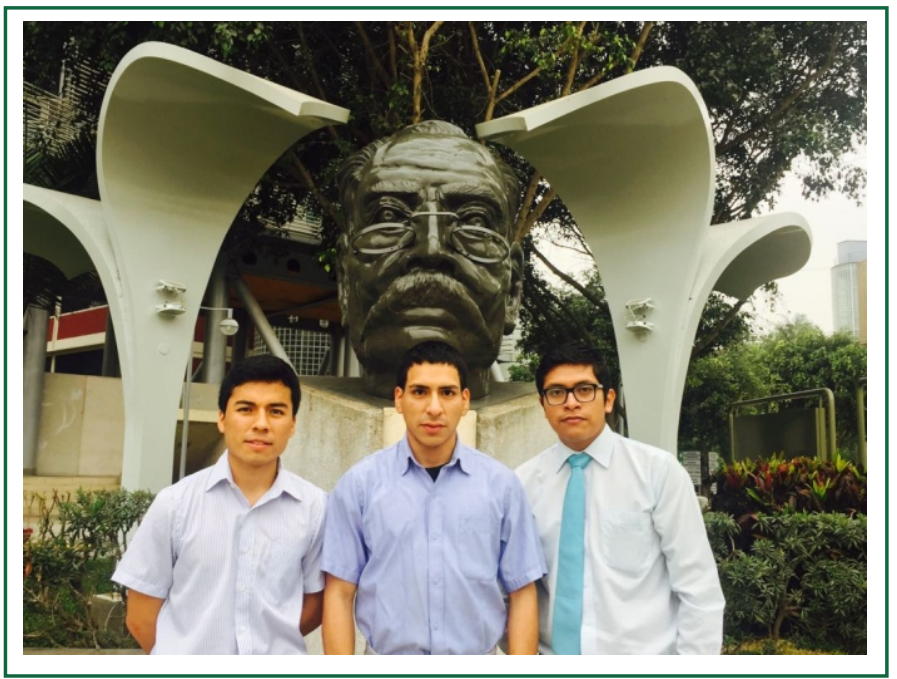

Recepción: 2017-04-11 / Aceptación: 2017- 06-23

\section{RESUMEN}

El objetivo es mostrar la organización y el proceso logístico en el área de abarrotes de un supermercado, así como su control de inventario con el fin de comprender la manera en la que una empresa lleva a cabo sus labores logísticas.

Palabras clave: Logística, distribución, inventarios, abastecimiento, organización, almacenaje.

\section{ABSTRACT}

The objective is to show the organization and the logistics process in the grocery area of a supermarket, as well as its inventory control in order to be able to understand the way in which a company carries out its logistics tasks.

Keywords: Logistics, distribution, inventories, catering, organization, storage. 


\section{INTRODUCCIÓN}

La logística desempeña un papel vital en los negocios, impulsa a las empresas a competir en el mercado a través de la fidelización hacia el cliente, lo cual actualmente es tomado como una filosofía por parte de las organizaciones.

La logística busca manejar estratégicamente la adquisición, el movimiento, el almacenamiento de productos y el control de inventarios, así como todo el flujo de información asociado, a través de los cuales las organizaciones y su canal de distribución se encauzan de modo tal que la rentabilidad presente y futura de la empresa es maximizada en términos de costos y efectividad. De esta manera, es como empresas que se encuentran en el rubro de supermercados e hipermercados trabajan en la actualidad buscando satisfacer las necesidades del consumidor a diario.

En el trabajo se explicará teóricamente el proceso logístico para luego dar paso a los elementos que este implica en cuanto a los productos denominados "abarrotes" del supermercado, además de conocer a fondo el control de inventario de dichos productos.

\section{RESULTADOS}

\section{Proceso logístico}

La globalización, así como la liberación de los mercados y del comercio de bienes y servicios, está requiriendo de las organizaciones o empresas usuarias y proveedoras de servicios una gestión con altos rendimientos. Dentro de este contexto, la logística se convierte en la estrategia más idónea para mejorar la eficiencia y eficacia de las empresas y así contribuir a mejorar su competitividad.

El proceso logístico muchas veces se ve reflejado en los sistemas empresariales dentro de los departamentos o áreas, aunque no siempre es de este mismo modo para todas las empresas. Respecto de sus características, es importante resaltar que la logística contempla actividades relacionales que integran a toda la empresa en función de sus objetivos. Esta es parte fundamental del desarrollo de su desarrollo, ya que con ello aseguran su permanencia en el mercado a través de un manejo eficiente de flujos y servicios hasta llegar al consumidor final, que es precisamente donde acaba este proceso, siendo los consumidores finales, con su satisfacción, los que en cierto modo dan a las compañías indicadores de si realiza o no una buena labor logística. Al mismo tiempo, ello depende de la gestión de cadena de suministros, enfocándose en la eficiencia de las actividades.

\section{Enfoque en procesos}

Un enfoque basado en procesos nos permite un mejor y continuo control sobre los procesos y las interrelaciones entre ellos, lo cual sin lugar a dudas representa una ventaja competitiva para la organización. Permite además un mejor desempeño y la obtención de mejores resultados, no solo en los procesos, sino también en los productos y servicios, así como la posibilidad de un mejoramiento continuo de manera integral.

Como en todo sistema, en este caso un sistema empresarial, se necesita de órganos que puedan trabajar relacionados entre sí para alcanzar 
uno o varios objetivos. El objetivo se basa en el proceso logístico, el cual necesita de un plan que lo respalde; es más, sea cualquiera el plan o los ejecutantes, todos estos cumplen una característica única: son una serie de procesos a seguir. $Y$ es justamente en la logística de cualquier empresa en donde se busca que dichos procesos se cumplan y que a su vez sean eficientes y capaces de abastecer todo el sistema, ya sea de entrada, operación o salida.

\section{Mejoramiento en procesos}

En la última década del siglo pasado, las empresas han aprendido la lección y buscan, cada vez con mayor decisión, mejorar íntegramente su ámbito de negocios. Ya no solo se trata de ofrecer productos y servicios de calidad (a la par de la competencia), sino de generar una modalidad nueva de hacer negocios y de entenderse a sí misma. Al cliente debe ofrecérsele no solo lo que espera, sino además ofrecer a nuestros clientes potenciales productos y servicios sorprendentemente buenos, para que se conviertan en clientes fieles.

Las empresas hoy se encuentran abocadas a abordar procesos de mejoramiento interno que les permitan sobrellevar todas estas nuevas exigencias y para ello están acentuando sus esfuerzos en aspectos tales como:

- Mejorar los niveles del servicio al cliente en todas las interfaces que la organización tiene con él (por sobre todos sus procesos logísti$\cos )$

- Desarrollar los procesos (tanto logísticos y productivos como de la empresa) a los más bajos costos y con los correspondientes márgenes deseados. Esta eficiencia de procesos y control de utilidades se advierte en aspectos tales como la depuración de procesos, reingeniería, cambios de tecnología, automatización, disminución de tiempo de ciclo de procesos, aplicación de los conceptos Pull y Just in Time (JIT), a los procesos productivos.

- Mantener una política de oferta que incluya la variedad de productos y la satisfacción de demanda estacional como variables estratégicas del negocio sobre la base de su constante cambio.

- Entregar, en la medida de lo posible, un alto valor agregado en los productos y servicios a los clientes, por encima de la satisfacción esperada por ellos. Esto implica generar salidas que contengan características valorables; las cuales, aunque no estén consideradas en el listado exigible como mínimo por el cliente, le sean interesantes y puedan inclinarlo a convertirse en cliente cautivo de la organización.

\section{MATERIAL Y MÉTODOS}

El trabajo está basado en una entrevista realizada al gerente comercial de frutas y verduras con experiencia en el área de abarrotes dentro de la misma empresa.

Durante la entrevista, se tocaron temas como cross docking, cubicaje, además del conocimiento sobre el Centro de Distribución San Francisco, que es el almacén principal de la tienda ubicada en Lurín, Lima. 


\section{RESULTADOS}

Se considera pertinente dividir la investigación en cinco partes: organización, empresa, valores, proceso logístico de "abarrotes" y control de inventario de los mismos en un supermercado.

\section{Organización}

El Supermercado pertenece a Supermercados Peruanos SA, que es una sociedad que forma parte del grupo denominado Intercorp, junto a otras veinte sociedades más. Todo esto empezó en el año 1994, cuando un grupo de empresarios adquirieron el Banco Internacional del Perú, que años más tarde pasaría a llamarse Banco Interbank, como lo conocemos hoy. Es dentro de este grupo donde se crea Supermercados Peruanos, que involucra a tres cadenas de venta de bienes y servicios.

Supermercados Peruanos SA está compuesto por:

Presidente:

- Carlos Rodríguez Pastor Persivale

Directores:

- Ramón Barua Alzamora.

- David Fischman Kalincausky

- Juan Carlos Vallejo Blanco.

- Julio César Luque Badenes.

- Pablo Hernán Turner Gonzales.

\section{Empresa}

Nace el año 1993 con el nombre de Santa Isabel y diez años después se vuelve parte del Grupo
Intercorp.

Es una de las primeras cadenas de supermercados en llegar a provincias, logrando presencia en veinticinco provincias de la costa, sierra y selva y contando hoy con más de cien tiendas para comodidad y satisfacción de más peruanos. Además, es una de las primeras cadenas peruanas en conseguir la certificación internacional HACCP para los alimentos frescos.

Cuenta con 15014 colaboradores (2016) y más de sesenta y cinco tiendas a nivel nacional.

\section{Valores}

Sus características básicas e imprescindibles son:

- Trabaja en equipo.

- Ordenado y honesto.

- Muy trabajador.

- Actitud innovadora.

- Servicial.

Dentro de su proceso de selección y de comunicación interna, utilizan una especie de "colaborador especial" Ilamado Tomas, que no es más que un tomate humanizado que representa estos valores antes mencionados, aparte, de ser el "comunicador" enlace entre gerencia y trabajadores (Supermercados Peruanos, 2016a)

\section{Proceso logístico de "abarrotes"}

La empresa opera en las regiones más importantes del Perú, tiene una participación destacada dentro del rubro de los supermercados. Aparte de ello, las operaciones de la empresa 


\section{Organigrama}

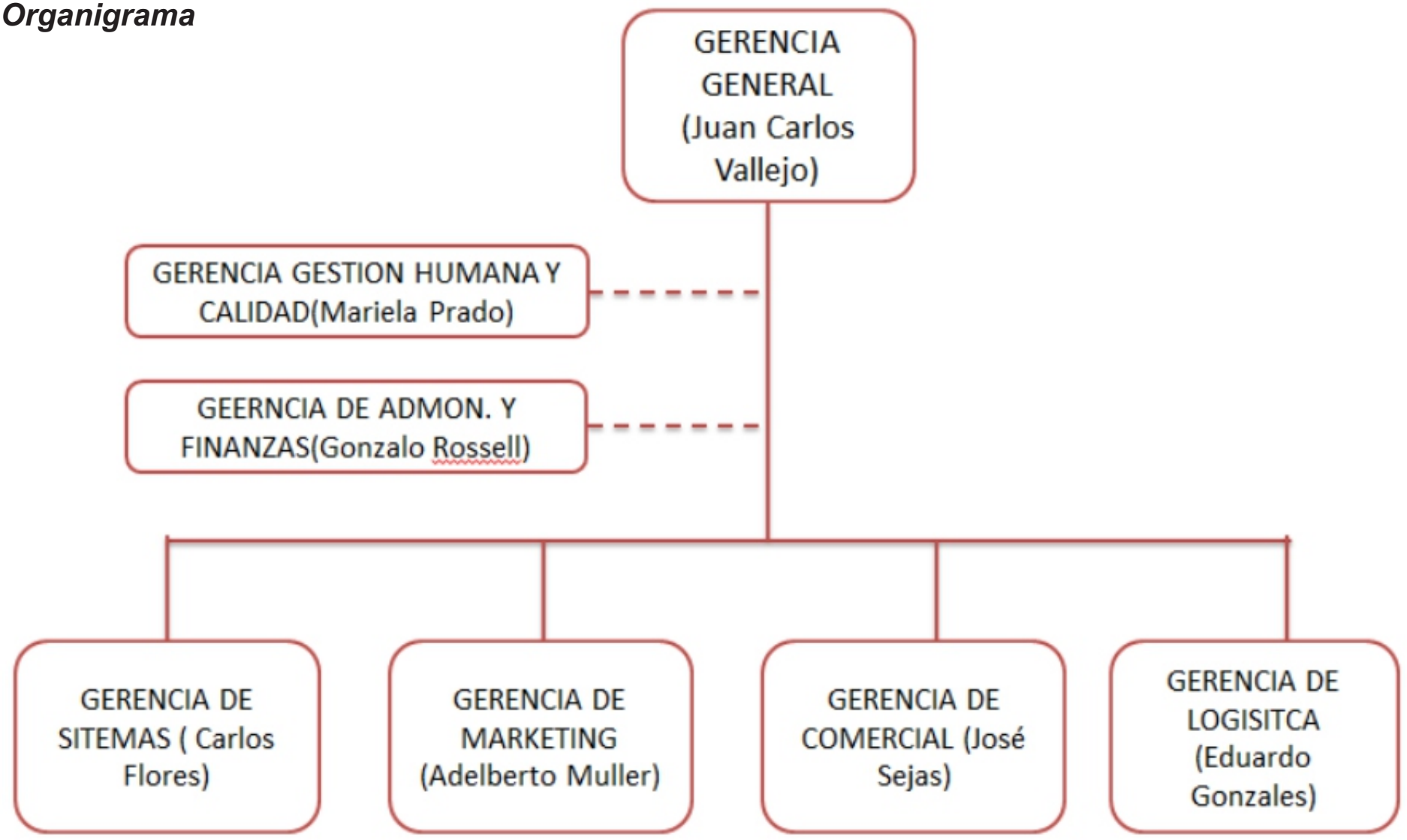

Figura 1. Organigrama general proporcionado por el gerente comercial de la empresa.

son grandes y complejas y varían dependiendo del producto, sección, zona, necesidad, etc. A continuación, se dará a explicar precisamente cómo funcionan las operaciones logísticas para el área de abarrotes del supermercado Plaza Vea.

Este proceso se divide principalmente en 3 partes.

\section{Cross docking}

A través de este proceso, se envía mercadería a la tienda sin haber descargado en el almacén central llamado Centro de Distribución (Lurín).

El proceso cross docking se utiliza dentro de la empresa para productos que almacenan mucho espacio, que a la vez significan mayor costo de almacenaje. Ejemplo: papel higiénico o pañales.

El procedimiento es como sigue:

1. Llegada de mercancías a través de los proveedores al CD de Lurín.

2. La mercadería pasa por un control dentro del CD San Francisco sin hacer ninguna descarga.

3. La mercadería ya inspeccionada pasa directamente a tienda.

\section{Directo}

En este proceso, la mercadería va directamente del proveedor a la tienda sin necesidad de pasar por el CD San Francisco. 


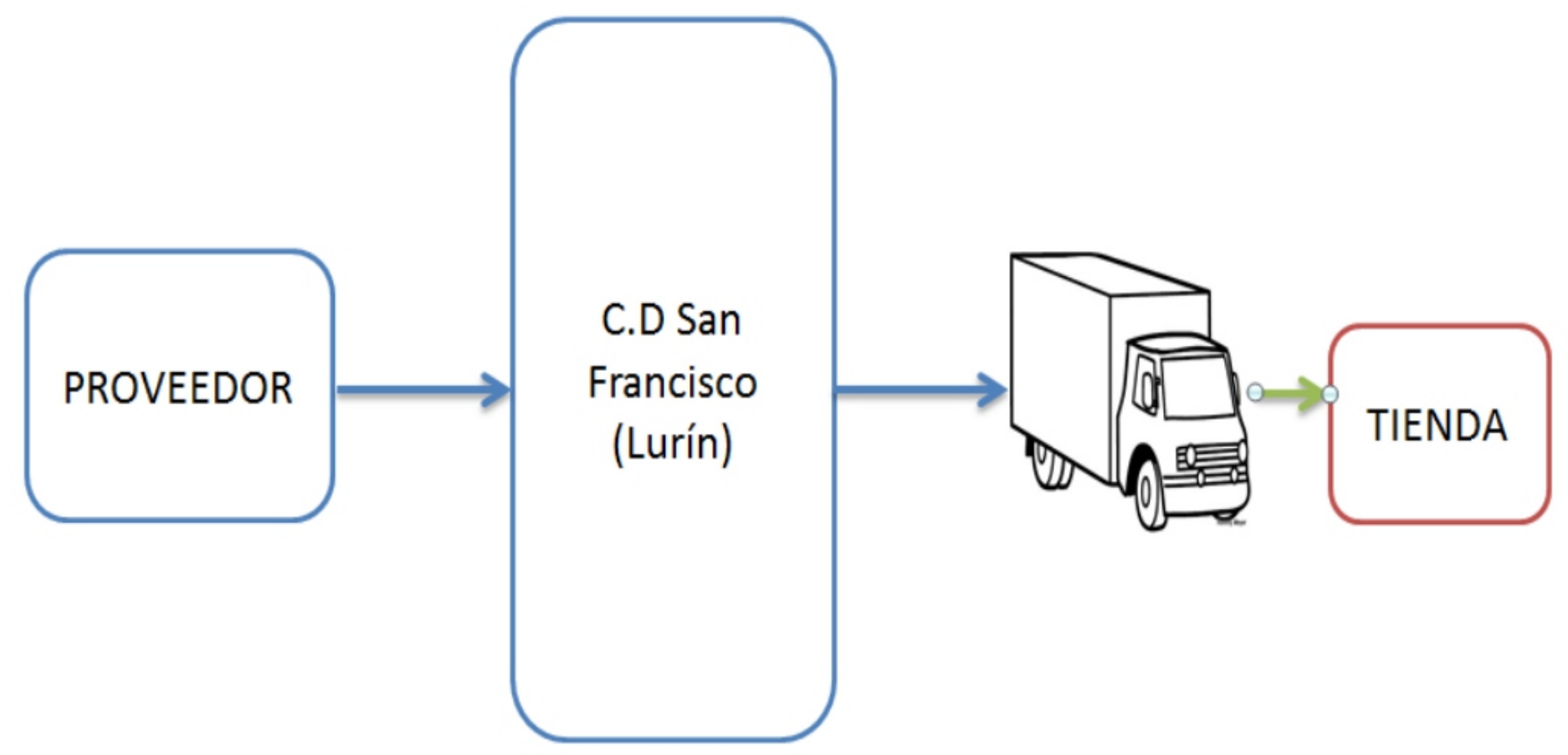

Figura 2. Ejemplo de cross docking.

Este método solo funciona con proveedores chicos y productos específicos. Actualmente, es tan poco usado que se evalúa su vigencia a futuro dentro del proceso logístico del supermercado.

\section{Distribución al CD San Francisco}

El proceso que se detalla a continuación quizás sea el más conocido o el que cualquier persona podría imaginarse al escuchar sobre un proceso logístico.

Básicamente, el proceso de distribución al CD San Francisco consiste en llevar los productos al almacén en Lurín, para luego, a través de camiones, se proceda a llevarlos a la tienda.

Es usado en casi todos los productos que puedan estar almacenados junto a otros, que tengan un largo tiempo de vida y que no ocupen mucho espacio en almacén.
El procedimiento es como sigue:

1. Llegada de mercancías a través de los proveedores al CD de Lurín.

2. La mercadería se descarga dentro del $C D$ San Francisco.

3. La mercadería pasa a almacén dentro del centro de distribución.

4. Se evalúa los requerimientos de cada tienda.

5. Se carga la mercadería a los camiones.

6. Los camiones de distribución van directamente a la tienda para ser vendidos.

Control de inventario de "abarrotes" en Plaza Vea

El Supermercado, así como cualquier otro supermercado, lleva un control de sus productos. En el caso de Plaza Vea, se realiza de la manera que veremos a continuación. 


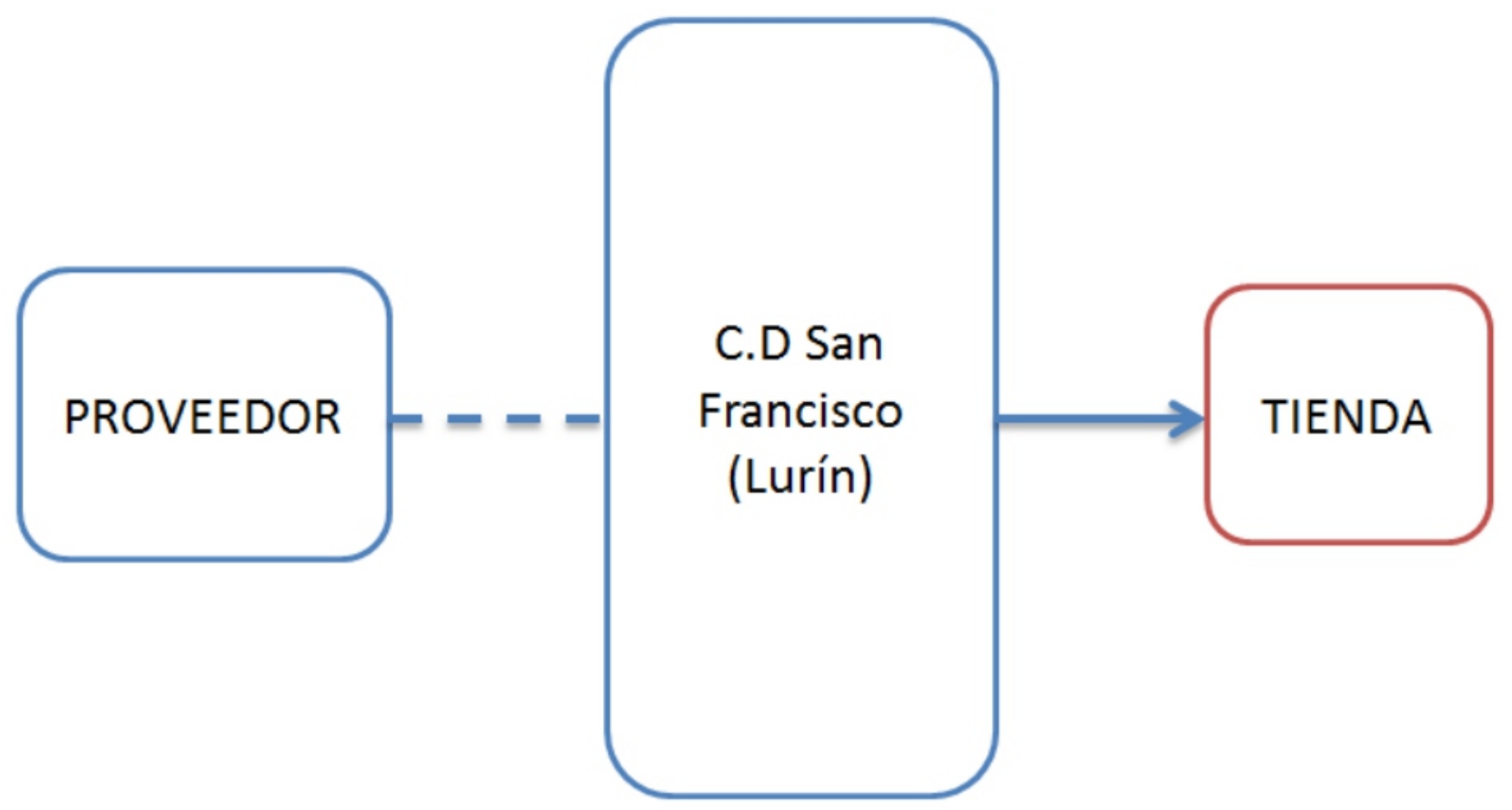

Figura 3. Ejemplo de distribución al CD de San Francisco.

Fuente: entrevista al actual gerente comercial de frutas y verduras. Elaboración propia.

En las góndolas se coloca una cantidad de un producto sin dejar ningún espacio en blanco, manteniéndolo siempre lleno para evitar una mala imagen y tener buenas críticas de los consumidores. El almacén tiene lo que vendría a ser la venta media del producto y así poder satisfacer la demanda de la tienda; la suma de lo que ponen en las góndolas más lo que se tiene en el almacén es lo que debería tener la tienda, para el correcto movimiento de su inventario en lo que respecta a abarrotes, tiene que poseer un stock de dos días .En el caso de Plaza Vea,

el cubicaje es demasiado cuidadoso, pues se intenta llenar todos los espacios del camión al momento de abastecer una tienda; además de ello, la tienda cuenta con los pallets para mejor movilización de la mercadería y el proceso de "picking" se realiza con cuidado para no dañar el producto al momento de acomodarlo en las góndolas.

Por ejemplo, imaginemos una góndola con cincuenta tarros de leche, la cual tiene una venta media de cincuenta tarros también, lo que suma cien tarros de leche. A este total se le suma el stock de seguridad, el cual normalmente es el doble del pedido real (que en este caso sería de cien tarros de leche). Cabe resaltar que el inspector revisa las góndolas cada hora con el fin de ver el consumo del producto y colocar nuevos productos si es necesario.

\section{CONCLUSIONES}

La empresa maneja no solo un excelente proceso logístico, sino también un correcto procedimiento de control de inventario de abarrotes, lo que genera no solo satisfacción en los consumidores, sino que también mantiene su nicho 
de mercado desde su fundación en el Perú.

\section{REFERENCIAS}

López, J. A. (2011).Logística. Gestión de compras, almacenes y transporte.Gestiópolis. Obtenido de: https://www.gestiopolis.com/logistica-ges tion-compras-almacenes-transporte/

Caro, R. E. (2014). El proceso logístico. Administración moderna. Obtenido de:http://www. administracionmoderna.com/2012/04/el-pro ceso-logistico.html

Herrera, C. V. (2010). Enfoque basado en procesos. Gestiopolis. Obtenido de: https://www. gestiopolis.com/enfoque-basado-procesos/
Revista Logistec (2013). Por qué mejorar los procesos logisticos en las organizaciones. Obtenido de: http://www.revistalogistec.com/ index.php/vision-empresarial/analisis/item/ 2342-por-que-mejorar-los-procesos-logisticos -en-las-organizaciones

Supermercados Peruanos (2016a). Colaboradores. Obtenido de: http://www.supermerca dosperuanos.com.pe/web/qsomos-colabora

Supermercados Peruanos (2016b). Empresa. Obtenido de: http://www.supermercados peruanos.com.pe/web/qsomos-empresa

Correo electrónico para correspondencia eduran_2006@hotmail.com 